\title{
Comparative transcriptome analysis of two reproductive modes in Adiantum reniforme var. sinense targeted to explore possible mechanism of apogamy
}

\author{
Qi Fu' and Long-qing Chen ${ }^{2^{*}}$ (D)
}

\begin{abstract}
Background: Apogamy is a unique asexual reproduction in the ferns, in which somatic cells of gametophytes go through dedifferentiation and then differentiate into haploid sporophytes bypassing fertilization. Restricted to the lack of genomic information, molecular mechanisms of apogamy have remained unclear. Comparative transcriptome analysis was conducted at six stages between sexual reproduction and apogamy in the fern Adiantum reniforme var. sinense, in an effort to identify genes and pathways that might initiate the asexual reproduction.

Results: Approximately 928 million high-quality clean reads were assembled into 264,791 unigenes with an average length of $615 \mathrm{bp}$. A total of 147,865 (55.84\%) unigenes were successfully annotated. Differential genes expression analysis indicated that transcriptional regulation was more active in the early stage of apogamy compared to sexual reproduction. Further comparative analysis of the enriched pathways between the early stages of the two reproductive modes demonstrated that starch and sucrose metabolism pathway responsible for cell wall was only significantly enriched in asexual embryonic cell initiation. Furthermore, regulation of plant hormone related genes was more vigorous in apogamy initiation.
\end{abstract}

Conclusion: These findings would be useful for revealing the initiation of apogamy and further understanding of the mechanisms related to asexual reproduction.

Keywords: Apogamy, Fern, Adiantum reniforme var. sinense, Gametophyte, Transcriptome

\section{Background}

As popular ornamental foliage plants, the ferns are now cultivated in many countries and have gradually gained more and more attention and increasing demand all over the world [1]. The species such as Adiantum and Drynaria are also considered as medicinal plants in curing the human disease in multiple fields. The central question for utilization of ferns concerns exploiting new germplasm resources and increasing the reproductive efficiency. Ferns are unique among land plants in having separate and autotrophic gametophytes and sporophytes. The gametophyte-tosporophyte ways for ferns possess two reproductive modes:

\footnotetext{
* Correspondence: clqhzau@126.com

${ }^{2}$ Southwest Research Center of Landscape Architecture Engineering (State Forestry and Grassland Administration), Southwest Forestry Universityy, Kunming 650224, China

Full list of author information is available at the end of the article
}

sexual reproduction and apogamy [2, 3]. Unlike the sexual reproduction features fertilization and zygotic embryogenesis, in apogamy the sporophytes are formed directly from somatic cells of gametophytes, without the intervention of sexual organs. It is estimated that $10 \%$ of the extant fern species reproduce obligately asexually by apogamy, perhaps as an adaptation to a harsh environment [4-6].

The induction of apogamy has been accomplished in many ferns by culturing gametophytes on exogenous substances, such as carbohydrates [2,7], osmotic conditions [8], and plant hormones including ethylene [9], auxins [10] and cytokinins [11]. However, the molecular mechanism and related signaling networks in controlling apogamy is still not entirely understood. So far, there are several studies focusing on the genes promoting the apogamy in Physcomitrella patens [12] and Ceratopteris richardii [13, 
14], trying to interpret the phenomenon. In $P$. patens, apogamy could result from deletion of the gene orthologous to the Arabidopsis thaliana CURLY LEAF (CLF), which encodes a component of Polycomb Repressive Complex 2 (PRC2). In C. richardii, overexpression of CrANT or $B n B B M$ could promote apogamy. In addition, apogamy commitment was suggested to be associated with stress and metabolism by suppression subtractive hybridization in C. richardii. In the apogamous fern Dryopteris affinis ssp. affinis, the phytohormone signaling and stress responses were proposed to participate in vegetative and reproductive gametophyte development by comparative analysis between transcriptome and proteogenome [15].

In apogamy, the pivotal step is that somatic cells of the gametophyte are reprogrammed to start the sporophytic developmental program. It shows a remarkable phenomenon of cell totipotency, which is just like the feature of somatic embryogenesis in seed plants. Coincidentally, a CrANT gene in Ceratopteris richardii, mirroring BABY BOOM in Brassica napus, has been certified to promote apogamy, indicating the genetic similarity between apogamy in ferns and somatic embryogenesis in angiosperms [14]. Generally, it is believed that the genes responsible for cell division and cell wall, and the genes related to plant hormones play a key role in triggering vegetative-to-embryogenic transition [16-18]. The studies of genes and signaling pathways related to vegetative-to-embryogenic transition would be benefit for understanding the mechanism triggering apogamy. With the further comparative research of the key genes, the evolutionary process of asexual reproduction might gradually become clear.

Adiantum reniforme var. sinense, an unifoliate species that belongs to the family of Adiantaceae, is a rare and endangered fern distributed in China [19, 20]. The fern has been successfully induced in vitro to form sporophytes through sexual reproduction and apogamy respectively in the previous research. The morphological and cytological observations revealed that no sexual organs differentiated on the gametophytes during the process of apogamy. The sporophytes developed with more number and faster frequency on a single gametophyte in apogamy compared with sexual reproduction, reflecting higher reproductive efficiency. The progeny would inherit the trait based on the character of asexual reproduction. Comparative studies of key stages of the two reproductive modes would constitute a significant step forward in understanding apogamy initiation.

This study is aiming to uncover the possible molecular mechanisms of apogamy in ferns at transcriptional level. Due to $A$. reniforme var. sinense is lack of reference genome, de novo assembly using high-throughput sequencing technology is an ideal method for transcriptome analysis. Therefore, RNA-seq was performed to explore the gene expression differences in gametophytes at six stages between sexual reproduction and apogamy. Comparative transcriptome analysis of early stages between the two reproductive modes was carried out to clarify the genetic basis for apogamy initiation. To our knowledge, this is the first attempt to use RNA-Seq to detect differential expression of genes in fern gametophytes conducting two reproductive modes. On the basis of bioinformatics analysis, it is expected that the results will help to reveal molecular mechanisms that responsible for apogamy in the ferns. In the future, the research on the function of key genes will be beneficial to create new germplasms with high reproductive efficiency in other ferns by transgenic technology.

\section{Results}

The morphogenetic characteristics of gametophytes for two reproductive modes

The reproductive status was defined by the morphologies of the gametophytes before construction of transcriptome library. In Fig. 1, the SG0, SG1 and SG2 respectively represented as the early, middle and later stages of sexual organs differentiation in sexual reproduction. Correspondingly, the AG0, AG1 and AG2 represented as the early, middle and later stages of asexual embryonic cells in apogamy. The gametophytes were morphologically similar between SG0 and AG0. The color was bright green and the thickness was slight. No sexual organs or asexual embryonic cells emerged on the surface. At SG1 stage, as the critical period of sexual organ differentiation, many outgrowths (namely sexual organs, including archegonia and antheridia) appeared on the gametophytes. The archegonia and antheridia were generally located in the middle and edge of gametophytes respectively. The color of sexual organs was green and darker than surrounding cells obviously. At AG1 stage, at the edge of gametophytes, somatic cells transformed to asexual embryonic cells and proliferated continually. The color was dark green obviously at these sites. These cells were extended to be the form of buds and then developed to sporophytes later. The two kinds of gametophytes presented different reproductive characteristics. The gametophytes both developed sporophytes at the stages of SG2 and AG2. The difference was that the apogamous gametophytes produced more sporophytes than sexual reproductive gametophytes. In addition, the juvenile fronds of sporophytes were oval shape in sexual reproduction and reniform shape in apogamy.

\section{De novo assembly of gametophytes transcriptome}

The high-throughput Illumina strand-specific RNA sequencing technology was employed to sequence the six stages of two reproductive patterns (three biological replicates for each stage, two biological replicates for SG2). Each sample was represented by at least 25 million reads. In total, 980 million short reads were generated from all samples, with 928 million high-quality clean reads selected 


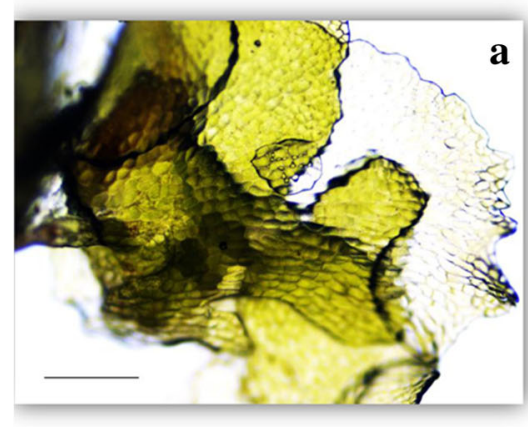

SG0

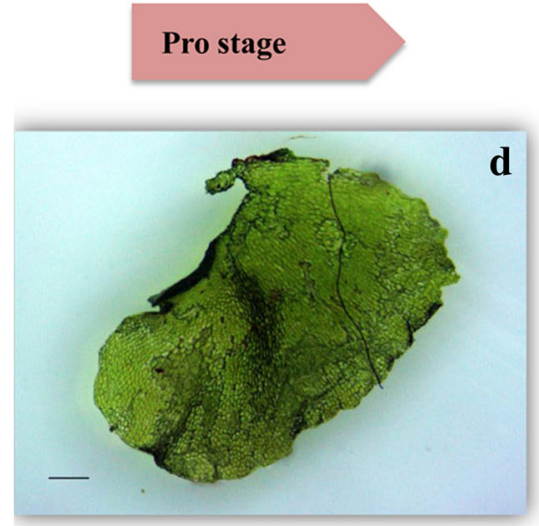

AG0

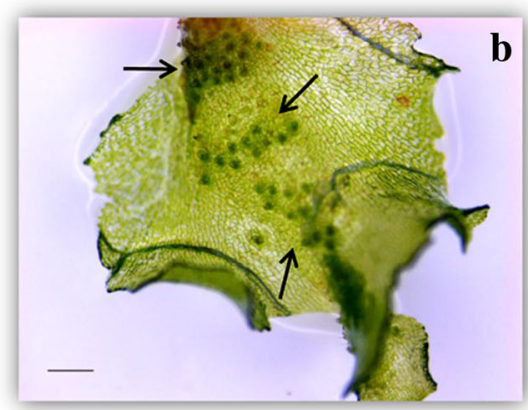

SG1

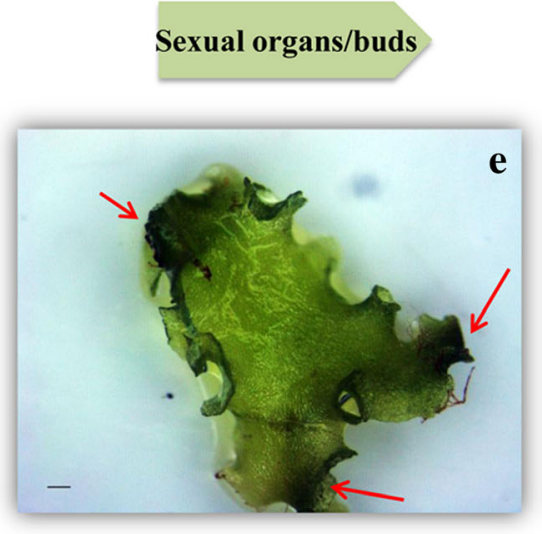

AG1

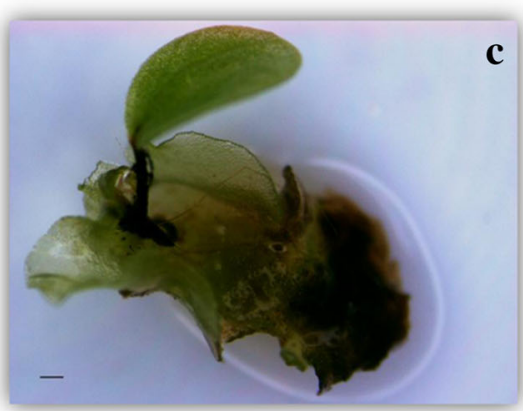

SG2

Post stage

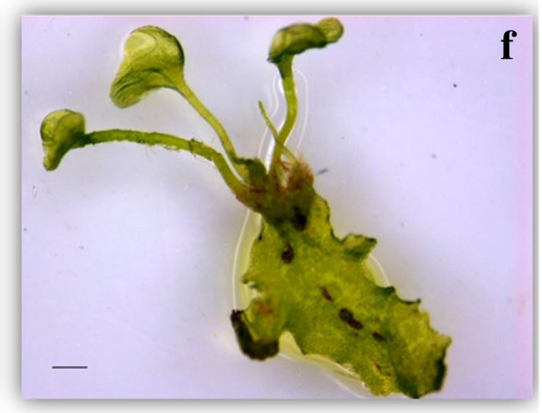

AG2

Fig. 1 Sexual reproduction and apogamy development stages in A. reniforme var. sinense gametophytes. a gametophyte with no sexual organs differentiation (SG0); $\mathbf{b}$ gametophyte with sexual organs initiation (SG1); c gametophyte with the sporophytes appeared (SG2); $\mathbf{d}$ gametophyte with no agamous buds appearing (AG0); e gametophyte with agamous embryonic cells initiation (AG1); $\mathbf{f}$ gametophyte with the apogamous sporophytes appeared (AG2). Black arrows, sexual organs; red arrows, asexual embryonic cells; Bar $=1 \mathrm{~mm}$

for further analysis. The de novo assembly was conducted by using Trinity software according to standard parameters. The assembly resulted in a total of 333,352 transcripts (no less than $200 \mathrm{bp}$ ) with a N50 of $1555 \mathrm{bp}$, and 264,791 unigenes with a N50 of 951 bp. The column diagrams of size distribution of transcripts and unigenes were shown (Additional file 1: Figure S1).

\section{Functional annotation of unigenes}

In order to obtain the comprehensive information of gene function, the unigenes were blasted using 7 databases $(\mathrm{Nr}$, Nt, KEGG, SwissProt, PFAM, GO and KOG) (Table 1). In total $147,865(55.84 \%)$ of all the assembled unigenes (264, 791 ) could be annotated. Approximately 12,753 (4.81\%) of the unigenes were simultaneously annotated by all databases. Nr analysis indicated that the top three species with the best hit were Physcomitrella patens (6.3\%), Selaginella moellendorffii (5.3\%) and Guillardia theta (4.5\%), all belonging to original plants (Additional file 2: Figure S2). GO analysis was performed to classify the function of annotated unigenes and categorized 112,366 unigenes belonging to three categories (biological process, cellular component and molecular function) in which 'cellular process' (61, 818), 'cell' (36,267) and 'binding Molecular Function' (61, 638) were the primary groups, respectively (Fig. 2).

To further evaluate the annotated transcriptome data, the sequences were compared with the KOG database. As a result, 67,950 unigenes were grouped into 26 categories (Fig. 3). 'General function prediction only' was the topmost category, with 9767 unigenes (14.37\%), followed by 'Posttranslational modification, protein turnover, chaperones' (9199, 13.54\%), 'Signal transduction mechanisms' (7572, 11.14\%), 'Translation, ribosomal structure and biogenesis' (6948, 10.23\%), 'Intracellular trafficking, secretion, and vesicular transport' (4854, $7.14 \%)$, 'Energy production and conversion' (4056, $5.97 \%$ ), and 'RNA processing and modification' (3864, $5.69 \%)$. Furthermore, 2426 (3.57\%) unknown functional unigenes were identified.

In addition, 51,831 unigenes were clustered to 32 KEGG pathways (Fig. 4). The majority of unigenes were grouped into pathways for 'Translation' (6422), 'Signal transduction' (5783), 'Carbohydrate metabolism' (4802) and 'Overview' (4271). 
Table 1 Statistics of annotation analysis of unigenes

\begin{tabular}{|c|c|c|c|}
\hline & Number of Unigenes & Percentage (\%) & Software and Parameters \\
\hline Annotated in $\mathrm{Nr}$ & 100066 & 37.79 & $\begin{array}{l}\text { NCBI blast 2.2.28+, } \\
\text { e-value }=1 \mathrm{e}-5\end{array}$ \\
\hline Annotated in $\mathrm{Nt}$ & 31003 & 11.7 & $\begin{array}{l}\text { NCBI blast 2.2.28+, } \\
\text { e-value }=1 \mathrm{e}-5\end{array}$ \\
\hline Annotated in KEGG & 51831 & 19.57 & $\begin{array}{l}\text { KAAS, KEGG Automatic Annotation Server, } \\
\text { e-value }=1 \mathrm{e}-10\end{array}$ \\
\hline Annotated in SwissProt & 92286 & 34.85 & $\begin{array}{l}\text { NCBI blast 2.2.28+, } \\
\text { e-value }=1 \mathrm{e}-5\end{array}$ \\
\hline Annotated in PFAM & 110651 & 41.78 & $\begin{array}{l}\text { HMMER } 3.0 \text { package, hmmscan, } \\
\text { e-value }=0.01\end{array}$ \\
\hline Annotated in GO & 112366 & 42.43 & $\begin{array}{l}\text { Blast2GO v2.5 and self-write the } \\
\text { Script, e-value }=1 \mathrm{e}-6\end{array}$ \\
\hline Annotated in KOG & 67950 & 25.66 & $\begin{array}{l}\text { NCBI blast 2.2.28+, } \\
\text { e-value }=1 \mathrm{e}-3\end{array}$ \\
\hline Annotated in all Databases & 12753 & 4.81 & - \\
\hline Annotated in at least one Database & 147865 & 55.84 & - \\
\hline Total Unigenes & 264791 & 100 & - \\
\hline
\end{tabular}

\section{Differential expressed genes (DEGs) analysis}

Differences in gene expression for six stages between the two reproductive processes were characterized, and DEGs were identified by pairwise comparisons across the six stages (Fig. 5). In sexual reproduction, 461, 59381 and 60715 DEGs were identified in pairs of SG1 vs SG0, SG2 vs SG1 and SG2 vs SG0 stages respectively. In apogamy, 5616, 645 and 9066 DEGs were identified corresponding to AG1 vs AG0, AG2 vs AG1 and AG2 vs AG0 stages. The total number of DEGs was higher in sexual reproduction compared with apogamy (Fig. 5a, b). In apogamy, the number of DEGs identified in early period (AG0 vs AG1, 5616) was more than that in later period (AG1 vs AG2, 645). On the other hand, this situation was reverse in sexual reproduction. The number of DEGs between SG0 and SG1 (461) was much fewer than that between SG1 and SG2 $(59,381)$. Furthermore, the number of DEGs between the corresponding stages of the two reproductive modes exceeded comparisons between different stages in each reproductive mode (Fig. 5c).

\section{Validation of RNA-seq data by quantitative real-time PCR (qPCR) analysis}

To confirm the reliability of the transcriptome analysis in the present study, nine DEGs were selected randomly

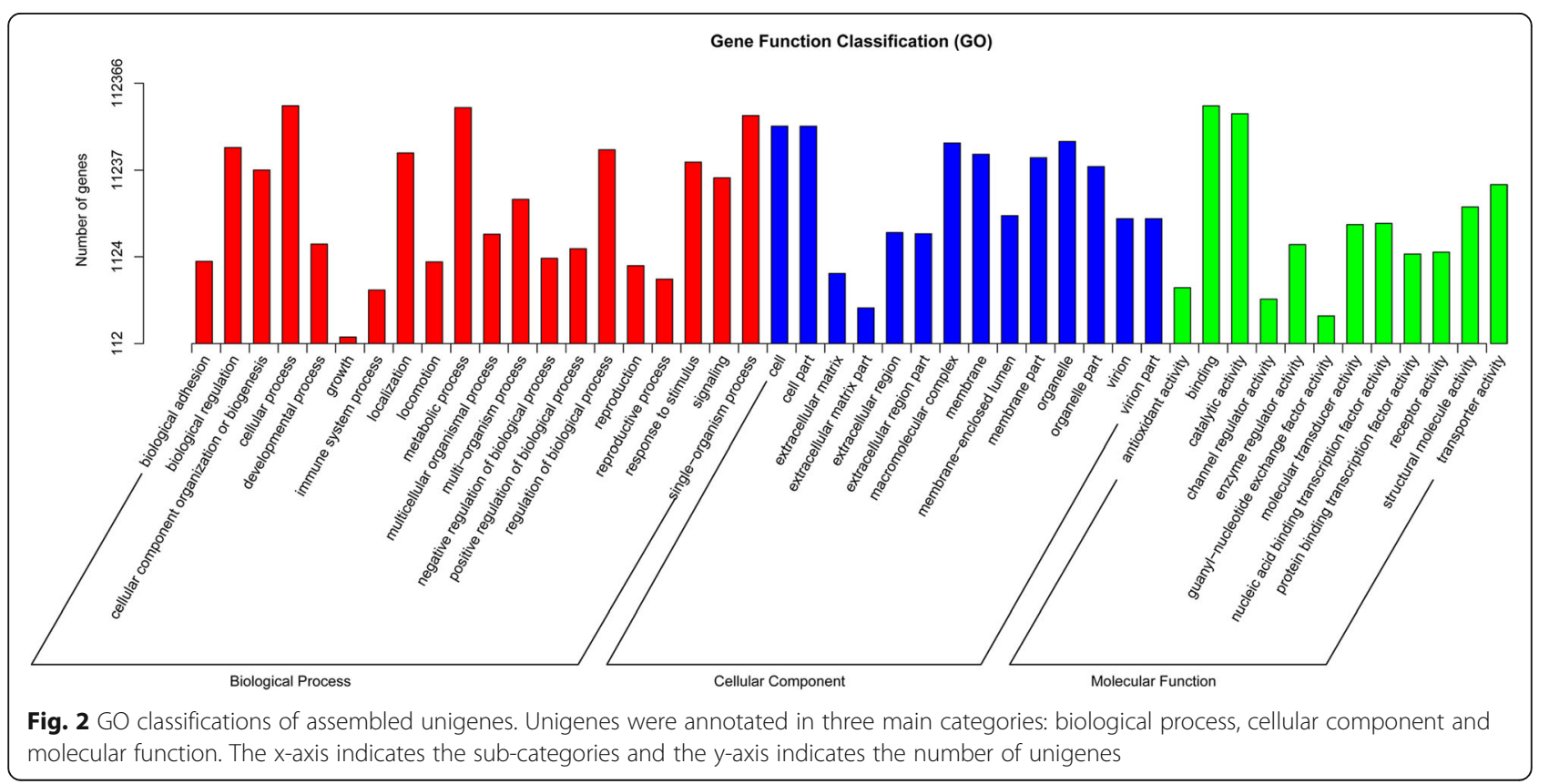




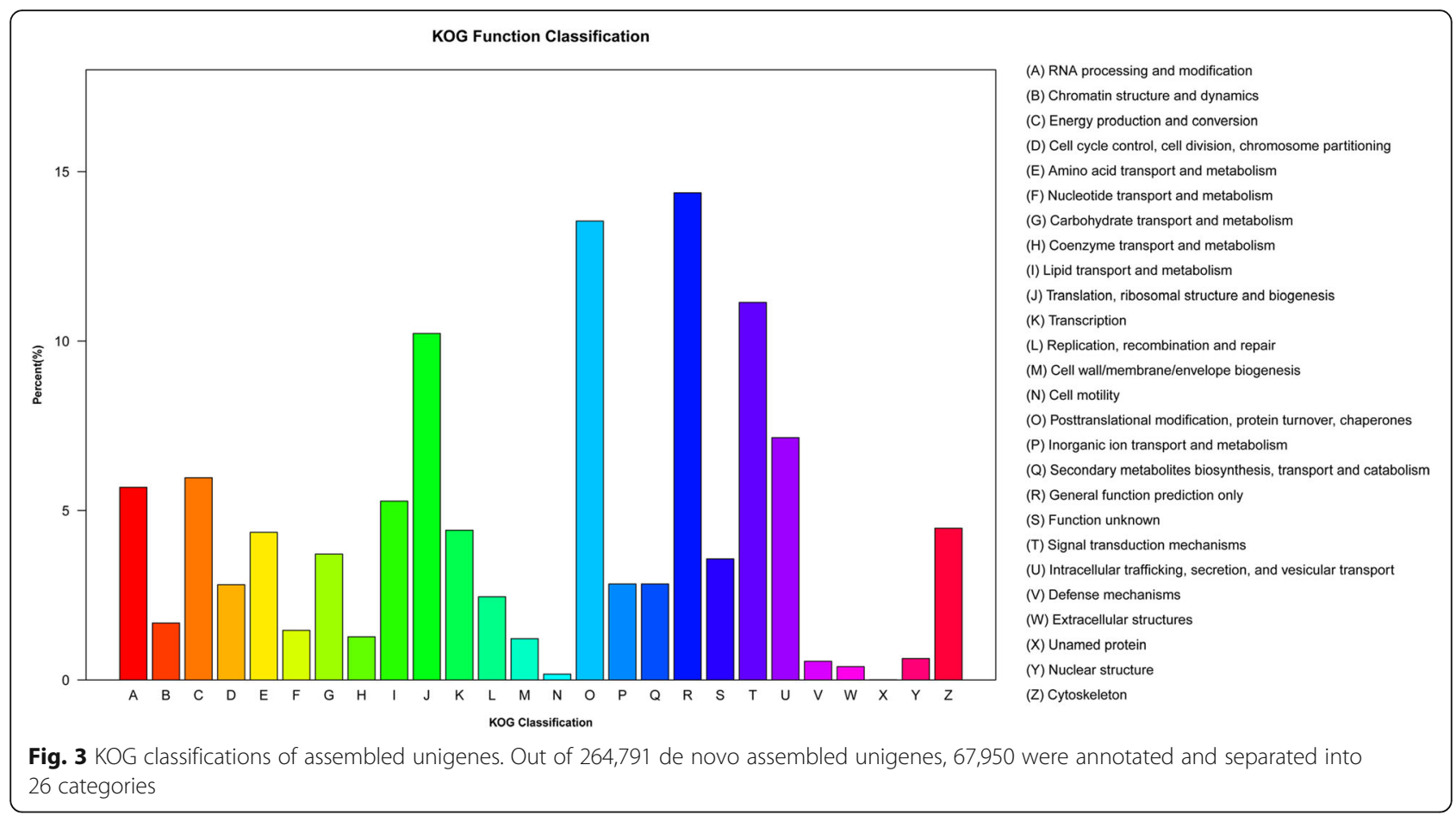

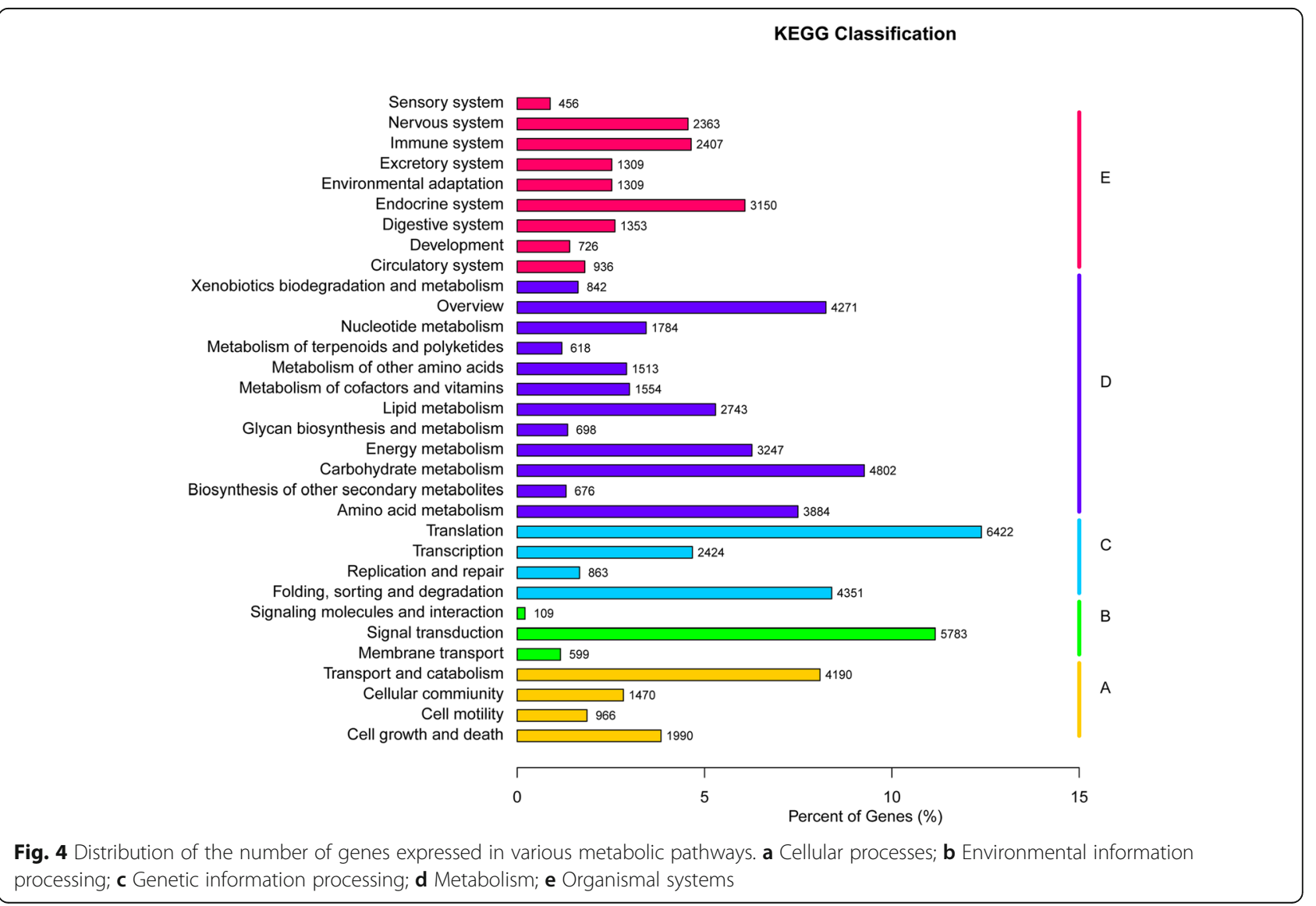




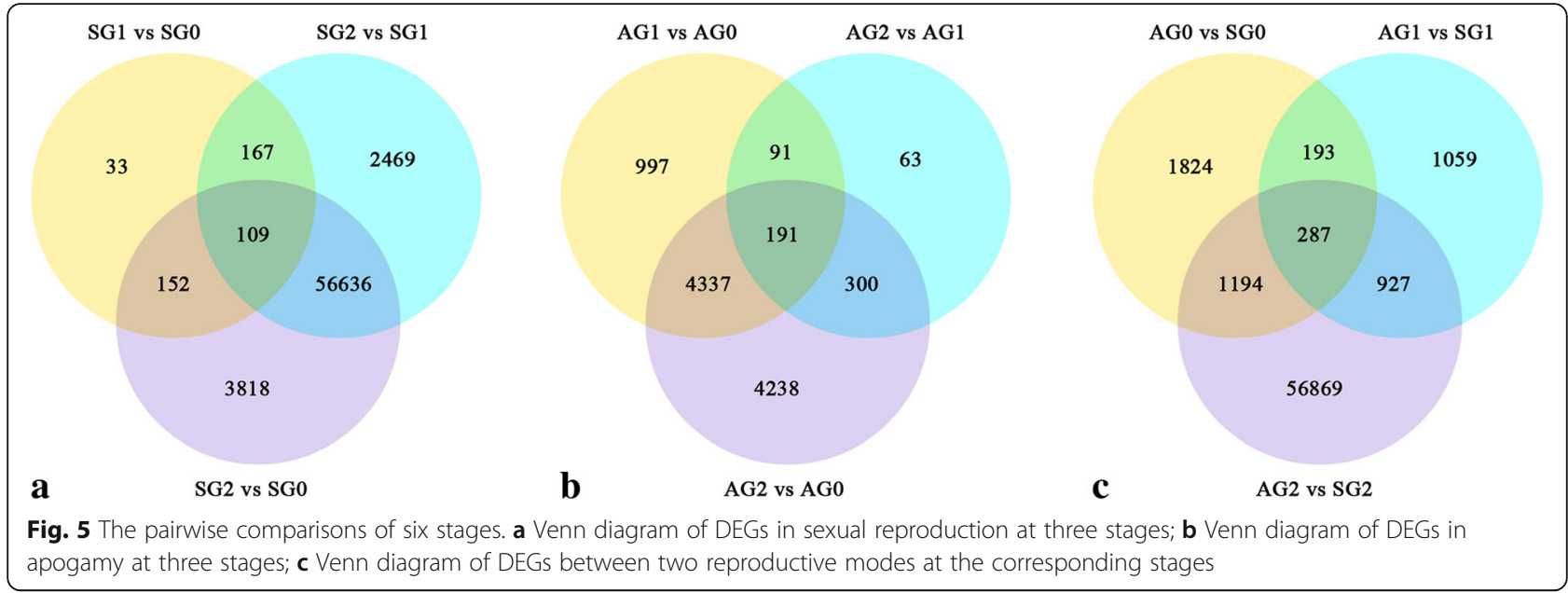

and their expression levels were validated by qPCR. The fold change determined by RNA-seq and qPCR showed a good consistency $(\mathrm{r}=0.780235, p<0.0001)$, demonstrating that the transcriptome analysis was accurate (Fig. 6). In addition, the expression levels of qPCR were consistent with the results of RNA-seq for each gene (Additional file 3: Figure S3).

\section{KEGG pathway classification of DEGs during sexual organ} and asexual embryonic cell initiation

To understand the biological functions of all the DEGs during sexual organ initiation, KEGG pathway enrichment analysis was carried out between SG0 and SG1. In total, 112 unigenes were clustered to 54 KEGG pathways, among which, only 10 pathways were significantly enriched (FDR $\leq$
0.05) (Additional file 4: Table S1, Additional file 5: Figure S4, a), including circadian rhythm, estrogen signaling and protein processing in endoplasmic reticulum pathway. Similarly, 2287 unigenes were clustered to 293 KEGG pathways, in which, 37 pathways were significantly enriched $(\mathrm{FDR} \leq 0.05)$ (Additional file 6: Table S2, Additional file 5: Figure S4, b) between AG0 and AG1, including flavone and flavonol biosynthesis, flavonoid biosynthesis, plant hormone signal transduction and starch and sucrose metabolism. The results of pathway enrichment analysis (Additional file 4: Table S1, Additional file 6: Table S2) contained pathways related to disease such as Toxoplasmosis, Measles, Influenza A and Pertussis. The genes involved in these pathways might be related to regulate the synthesis of compounds curing the disease in the fern. The pathways of

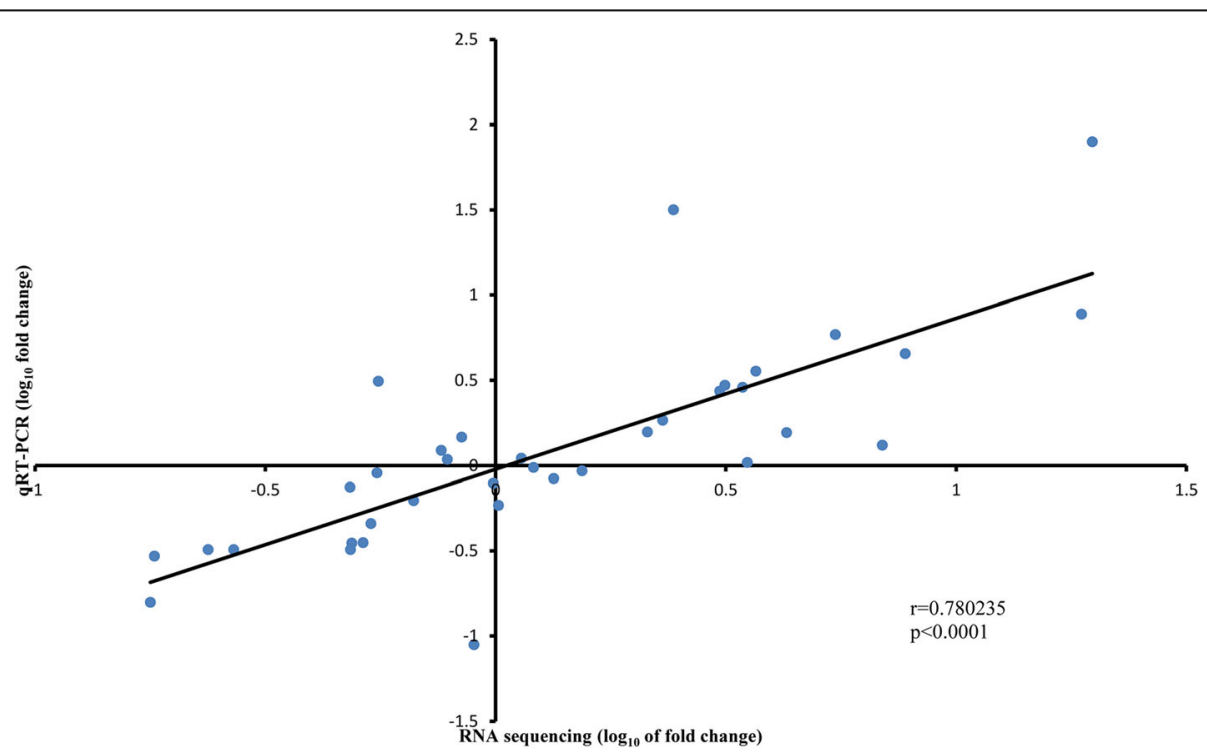

Fig. 6 Correlation between $\mathrm{qPCR}$ and RNA sequencing for the nine selected genes. Each point represents a value of fold change of expression level at G1 or G2 comparing with that at G0 or G1. Fold-change values were $\log _{10}$ transformed 
the two reproductive modes that the DEGs enriched in showed some differences. Considering the role of carbohydrates metabolism and plant hormones in inducing apogamy, starch and sucrose metabolism and plant hormone signal transduction pathways that only significantly enriched in AG0 vs AG1 were first concerned.

\section{Genes in starch and sucrose metabolism pathway related to asexual embryonic cell initiation}

KEGG pathway analysis presented that starch and sucrose metabolism pathway was only significantly enriched in asexual embryonic cell initiation. In total 57 unigenes were derived from identified DEGs involved in starch and sucrose metabolism pathways in Additional file 6. The expression levels of these genes were compared between the two reproductive patterns (Fig. 7, Additional file 7: Table S3, Additional file 8: Data S1). Most of the genes involved in glucose and pectin metabolism pathway, including beta-glucosidase, pectinesterase and UDP-glucuronate 4epimerase, were down-regulated at AG1 stage compared with AG0 stage, and most of them had higher expression in SG1 stage. Sucrose, amylum and trehalose related genes, such as sucrose-phosphate synthase (SPS), alphaamylase and trehalose 6-phosphate synthase (TPS) were up-regulated at AG1 stage compared with AG0 stage, while showed reverse trends between SG1 stage and SG0 stage.

\section{Genes in the plant hormone signal transduction pathway}

The regulation of exogenous hormones plays a key role in induction of apogamy in the ferns. According to the transcriptome data, plant hormone signal transduction pathway was enriched significantly accompanied with the differentiation of asexual embryonic cells (Additional file 6: Table S2), and appeared clearly in the top-20 enriched KEGG pathways during the sexual organ differentiation process (Additional file 4: Table S1). The expression levels of 35 genes (33 from Additional file 6, Table S2 and 2 from Additional file 4, Table S1) were compared at the six stages between the two reproductive patterns (Fig. 8, Additional file 9: Table S4, Additional file 10: Data S2).

In auxin signal transduction pathway, four transport inhibitor response protein 1 (TIR1) genes (c102726_g3, c107213_g1, c237894_g1, c90812_g1) were identified to express increasingly accompanied with the differentiation of asexual embryonic cells, while the expressions had no obvious changes during the sexual organ differentiation. Three $A u x / I A A$ genes were down-regulated at AG1 stage compared with AG0 stage. Interestingly, one GH3 gene

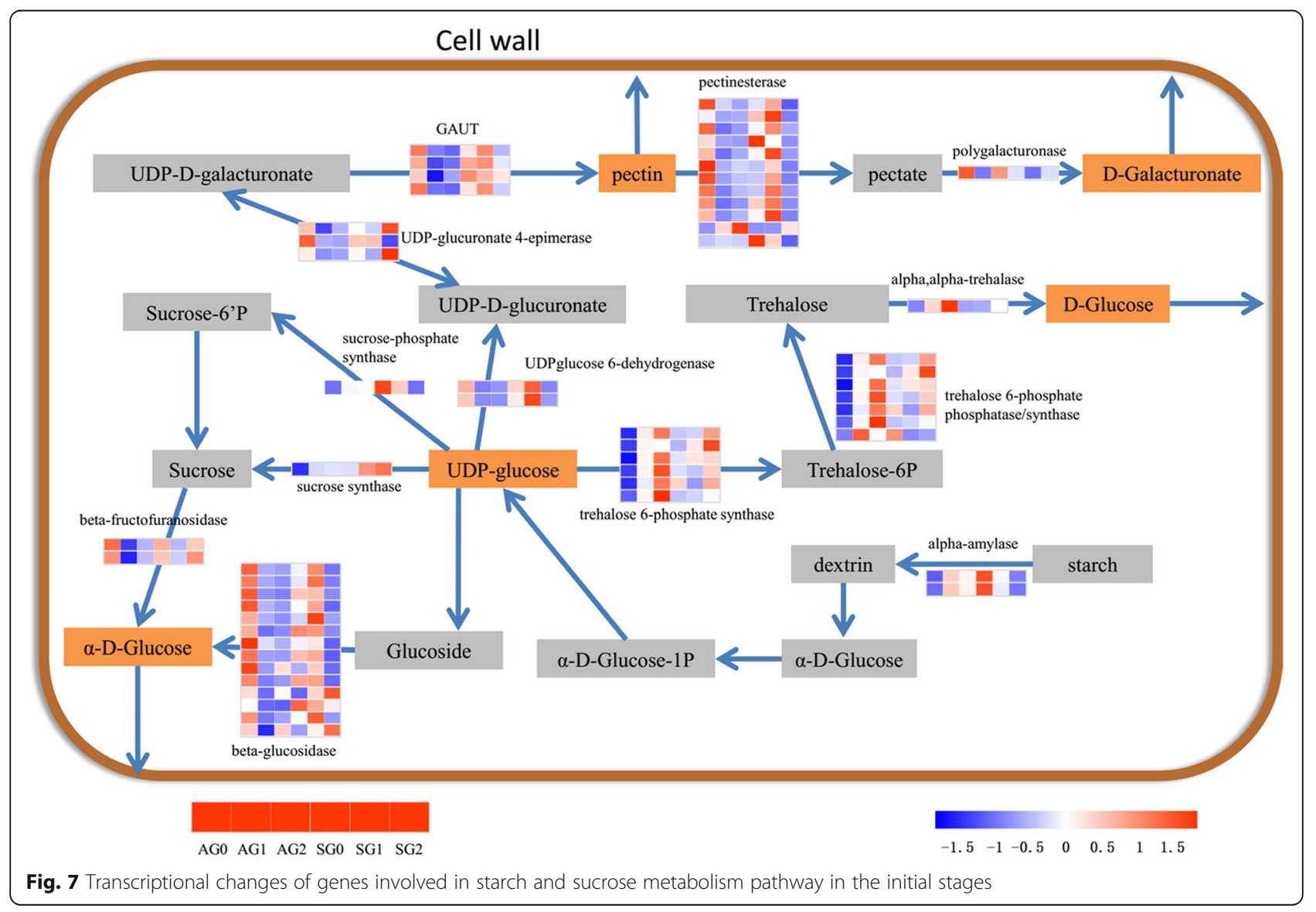




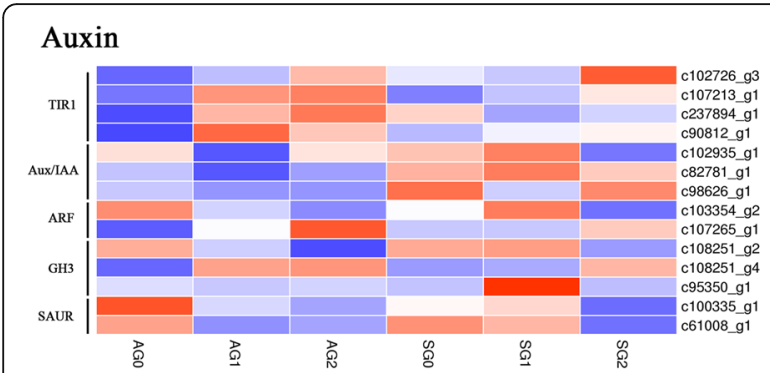

Cytokinine (CTK)

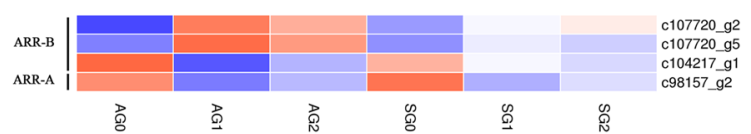

Gibberellin (GA)

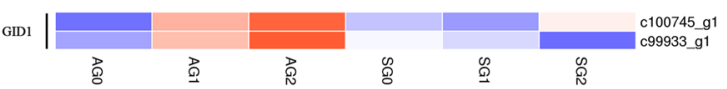

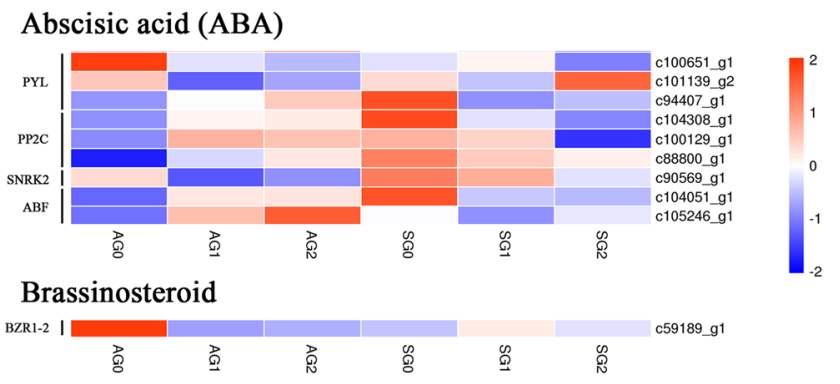

Jasmonic acid (JA)

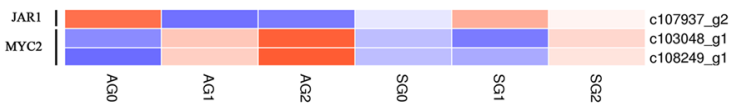

Salicylic acid

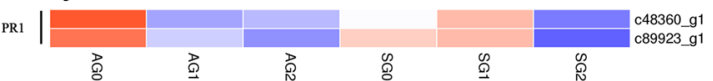

Fig. 8 Transcriptional changes of genes associated with plant hormone signal transduction pathway in gametophytes

(c95350_g1) was expressed extremely at higher level at SG1 than any other stages.

Two gibberellin insensitive dwarf1 (GID1) genes (c100745_g1, c99933_g1) associated with gibberellin metabolism showed higher expression levels in AG1 than in AG0, while the expression levels decreased during sexual organ differentiation.

In abscisic acid metabolism, most genes were upregulated significantly between AG1 and AG0, while were down-regulated between SG1 and SG0, such as protein phosphatase 2C (PP2C) (c104308_g1, c100129_g1, c88800_ g1) and ABRE binding factors $(A B F)$ (c104051_g1, c105 246_g1).

$M Y C 2$, a $b H L H$ transcription factor, plays a crucial role in the jasmonic acid signalling pathway. Two $A$. reniforme var. sinense genes were identified: c103048_g1 and c108249_g1. Both were highly expressed at AG1 stage compared with AG0 stage while showed lower expression at SG1 than SG0. However, the JAR1 (c107937_ g2) gene showed reverse expression trend.

In salicylic acid phytohormone pathway, two PR1 genes were identified: c48360_g1 and c89923_g1, both genes were down-regulated with the differentiation of asexual embryonic cells and showed higher expression levels at SG1 stage.

\section{Discussion}

RNA sequencing and de novo assembly of gametophyte transcriptome

Revealing the regulatory mechanisms of apogamy by RNAseq provides an advantageous resource for investigations into the genetic control of apogamy in ferns and comparisons with the asexual processes of higher plants. In $C$. richardii, a SSH study was conducted and 170 unique sequences associated with apogamy commitment were detected [13]. In this study, many more unigenes and pathways responsible for apogamy were identified using RNAseq technology, which may thus be helpful to further explain the mechanism inducing apogamy and sexual reproduction at transcriptional level.

In total, 147,865 unigenes were annotated to the 7 databases, which rated $55.84 \%$ of all the assembled unigenes $(264,791)$. The abundant information of gene number and annotation was more than other studies using nextgeneration sequencing techniques to characterize the transcriptome of fern gametophytes, such as Pteridium aquilinum and Lygodium japonicum [21, 22].

\section{Global changes of gene expression between sexual reproduction and apogamy}

Compared to sexual reproduction, less DEGs were identified in apogamy as a whole. By pairwise comparisons, the number of DEGs between AG0 and AG1 was more than that between AG1 and AG2, indicating that more complicated behaviors at transcriptional level occurred in asexual embryonic cell differentiation. However, the situation was inverse in sexual reproduction. The sporophyte formation phase had much more DEGs than sexual organ differentiation phase. These results suggested that the two reproductive patterns had different transcriptional regulatory networks. In addition, the factors affecting the initiation of apogamy had clearly developed a more complicated mechanism.

Cell wall biosynthesis should be one of the key processes affecting the apogamy initiation in the ferns

In the current study, apogamy initiation affected by the starch and sucrose metabolism pathway was investigated. 
Through the comparison of KEGG enrichment analysis, the sexual organs and asexual embryonic cells differentiation had different metabolic pathways and transcriptional profiles. The starch and sucrose metabolism pathway related to cell wall biosynthesis was only significantly enriched in the stage of asexual embryo differentiation. The DEGs involved in this pathway were expressed diversely in apogamy and sexual reproduction. The genes related to TPS/TPP, amylase, sucrose synthase (SUS) and SPS all expressed actively while the genes related to betaglucosidase and pectinesterase were suppressed during the process.

The amylase, SUS and SPS are the plant enzymes thought to play a positive role in cell wall synthesis [2326], while the beta-glucosidase and pectinesterase are considered to degrade the cell wall $[27,28]$. The change of expression levels of related genes in this pathway exactly demonstrated the cell wall was facilitated to generate during the asexual embryo differentiation process. Early apogamy involves differentiated somatic cells obtaining embryogenic competence and proliferating as embryogenic cells. This demands strict spatio and temporal control over cell division and elongation. The initiation of cell division is a key event during initial as well as subsequent steps of apogamy. Thus, apogamy should rely on accumulation of cell wall and regulation of signal molecules connected with the cell wall. The expression of genes mentioned above that responsible for cell wall might lead to the initiation of apogamy. However, it is necessary to validate the regulating relationship between the genes and apogamy experimentally in the future.

Moreover, the expression of SPS related gene (c108270_ g1) was up-regulated and down-regulated during the differentiation of asexual embryo and sexual organ respectively. The expression of SUS (c105466_g1) maintained upregulated in both processes. The expression trends of the genes were similar in the proliferation of somatic embryos in Picea. The activities of SPS increased while SUS levels stayed constant during the proliferation of somatic embryos [29, 30]. SUS and SPS are the plant enzymes believed to play a major role in sucrose biosynthesis and cellulose synthesis for cell wall [23-25]. The effects of sucrose on induction, maintenance, and maturation of somatic embryos also have been studied [31]. Taken together, the results showed that the SPS related genes might participate in regulation of asexual embryonic cells induction in apogamy.

In the present study, the TPS/TPP related genes were upregulated significantly during the asexual embryonic cells differentiation while were down-regulated or had no differential expression in the sexual organ differentiation. Notably, the TPS/TPP is regarded to modulate the plant development and verified to regulate cell shape and plant architecture [32, 33]. The cell shape is acquired during the process of cellular differentiation. Expression of AtTPS1 has been involved in carbon metabolism and specific developmental phenotypes, such as altered shoot growth and transition to flowering [34]. In tobacco, expression of TPS resulted in lancet-shaped leaf morphology [35]. In Arabidopsis, TPS was demonstrated to involve in the control of pavement cell shape and trichome branching [32]. Referring to somatic cells of gametophytes were triggered into asexual embryonic cells and then changed the cell shape and gradually developed to be outgrowths (sporophytes), the morphological changes showed the TPS played a vital function in apogamy. All these results suggested that the trehalose metabolism pathway was more active in apogamy than sexual reproduction, and thus might be one of the key processes influencing the apogamy.

Furthermore, overexpression of poplar xylem sucrose synthase in tobacco leads to a thickened cell wall [36]. Homozygous null mutants of AtTPS1 displayed cell wall thickening and altered morphology [37, 38]. In the present study, the appearance of the asexual embryonic cells differentiation regions on gametophytes turned dark green, indicating that the cell walls were thickened. It is inferred that the differential expression of the related genes might participate in the process and explained why the color of the asexual embryonic cells was deepened.

\section{Regulation of plant hormone related genes was more active in apogamy initiation}

In many fern species, apogamy can be effectively induced in suitable media supplemented with various plant hormones $[10,39]$ and phytohormone signaling proteins were supposed to participate in the apogamy [15]. It was noted in this study that more plant hormone related genes were regulated significantly during the early stage of apogamy, suggesting the embryogenic transition might be controlled by the expression of these genes.

The cell division is an important phenomenon for somatic cells dedifferentiation in apogamy. The auxin regulates cell division through causing hyperpolarization of the plasma membrane [40]. This is also a precondition for various auxin-triggered biological actions [41]. Auxin signaling is considered to play an important role in the molecular mechanism that controls the embryogenic transition of plant somatic cells [42]. In seed plants, auxin is one of the efficient initiators of somatic embryogenesis $[43,44]$. In the present study, the comparative KEGG enrichment analysis between the two reproductive patterns in the fern indicated that numerous auxin-related genes, such as TIR1, Aux/IAA, ARF, GH3 and SAUR, were transcribed significantly during the apogamy initiation. As the auxin receptor, the expression levels of TIR1 genes were all up-regulated during early apogamy, indicating that auxin-signaling pathway functioned actively. The expression of ARF1 gene (c103354_g2) gradually declining in 
apogamy was similar to the gene expression in somatic embryogenesis-induced explants in Arabidopsis [42]. These results indicated that auxin-related genes in the study should be critical regulators in influencing vegetative-to-embryogenic transition in apogamy initiation.

On the other hand, the GH3 gene (c95350_g1) involved in the auxin pathway enriched in the sexual organ initiation had dramatically higher expression at SG1 stage than other stages. In soybean, GH3 expression is restricted largely to specific tissues within organs of the developing flowers and expressed transiently during flower development [45]. This demonstrated that this gene might transiently participate in the sexual organ initiation.

Gibberellins are plant hormones directly related to important plant growth and development events including flowering and ovule development [46, 47]. GID1 is a gibberellin receptor previously identified in plants and associated with reproductive development [48]. In the present study, two GID1 genes were induced in the two reproductive patterns. This result was similar to the findings in Arabidopsis where the expression of GID1 was essential for reproduction $[48,49]$. The expression levels of GID1 increased and decreased during the initial stage of apogamy and sexual reproduction respectively, indicated that contrary effects of gibberellin regulation between the two reproductive patterns. In Brachiaria brizantha, GID1 is only expressed in the nucellus of apomixes compared with sexual reproduction, previous to aposporous initial differentiation [50]. There are sufficient reasons to believe that the function of GID1 might be related to apogamy initiation and conserved in evolution.

Plant hormone $\mathrm{ABA}$ is discovered in a wide range of land plants, from mosses to angiosperms. The ABA signaling is associated with both the abiotic stress responses and developmental regulation [51, 52]. The genes, c104308_g1, c100129_g1 and c88800_g1, were annotated as PP2Cs, the abundances of which increased significantly from AG0 to AG1 and decreased from SG0 to SG1. Interestingly, the PP2Cs were demonstrated to alter morphogenesis in Physcomitrella [53]. The transgenic plants overexpressing PP2Cs had continuous growth of archegonia (female organ) yet with few sporophytes forming compared to the wild type. Considering no fertilization occurs in the apogamy, these results indicated that the PP2Cs might have the effect of inhibiting the function of sexual organs.

Signal transduction pathways were also analyzed for other hormones, jasmonic acid and salicylic acid, according to the KEGG enrichment analysis. The genes, having increasing and decreasing expression levels in apogamy and sexual reproduction respectively, including $A B F$, $M Y C 2$ related to asexual embryonic initiation were observed. Notably, these genes have been proved to play an important role in stress responses $[54,55]$. It has been suggested that an increase in metabolic activity and stress responses together induces the apogamy commitment in C. richardii [13] and many proteins related to responses to biotic or abiotic stimuli are identified in the apogamous fern Dryopteris affinis ssp. affinis [15]. Accordingly, it is speculated that apogamy might be adapted to a harsh environment in early evolution.

Generally, plant biological activity is not only modulated by one hormone signal transduction pathway, thus the biological phenomenon often represents the results of the combined interplay of several different hormone signal transduction pathways. The interactions of these hormone-responsive genes for affecting apogamy need to be verified in future.

\section{Methods}

\section{Plant material}

The spores of $A$. reniforme var. sinense were obtained from mature sporophylls of the sporophytes cultured in the greenhouse at Huazhong Agricultural University (Wuhan, China). The gametophytes were induced from the spores and sterile cultured in the culture room, in Laboratory of Genetic Resources of Landscape Plants, Huazhong Agricultural University (Wuhan, China). The culture condition was under a 16/8-h (light/dark) photocycle at $25 / 20^{\circ} \mathrm{C}$ (day/night).

Two reproductive modes of gametophytes, sexual reproductive gametophytes (SG) and apogamous gametophytes (AG), were used for transcriptome analysis. Total six stages of tissues from two reproductive modes were collected. The sexual reproductive gametophytes contained: gametophytes with no sexual organs differentiation (SG0), gametophytes with sexual organ initiation (SG1), gametophytes with the sporophytes appearing (SG2). The apogamous gametophytes contained: gametophytes with no agamous buds appearing (AG0), gametophytes with agamous embryonic cells initiation (AG1), gametophytes with the apogamous sporophytes appearing (AG2). The samples of each stage were sampled at the same time, transferred immediately to liquid nitrogen, and stored subsequently at $-80^{\circ} \mathrm{C}$ until RNA extraction. Three biological replicates were collected for each stage (except the SG2 stage had two replicates). These samples were also collected and frozen immediately in liquid nitrogen and kept at $-80^{\circ} \mathrm{C}$ for the experiments of qPCR analysis.

\section{RNA isolation, library construction and sequencing}

Total RNA was extracted using the RNeasy Mini Kit (Qiagen, Valencia, CA, USA) according to the protocol provided by manufacturer. The integrity of RNA was determined by electrophoresis in $1 \%$ agarose gel. RNA quantity and quality were assessed using a NanoDrop ${ }^{\mathrm{mm}}$ 2000 spectrophotometer (Thermo Scientific) and an Agilent 2100 Bioanalyzer (Agilent Technologies, CA, USA). The samples showing A260/A280 ratio of 1.8-2.0 and 
an A260/A230 ratio of 2.0-2.2, and with RNA integrity number (RIN) greater than 8.0 were used for subsequent analysis. The samples were subsequently used in cDNA library construction and Illumina sequencing which was completed by Beijing Novogene Bioinformatics Technology Co., Ltd.

A total amount of $3 \mu \mathrm{g}$ RNA per sample was used as input material for the RNA sample preparations. Sequencing libraries were generated using NEBNext ${ }^{\circ}$ Ultra $^{\mathrm{Tm}}$ RNA Library Prep Kit for Illumina ${ }^{\circ}$ (NEB, USA) following manufacturer's recommendations and index codes were added to attribute sequences to each sample. Briefly, mRNA was purified from total RNA using poly$\mathrm{T}$ oligo-attached magnetic beads. Fragmentation was carried out using divalent cations under elevated temperature in NEBNext First Strand Synthesis Reaction Buffer (5X). First strand cDNA was synthesized using random hexamer primer and M-MuLV Reverse Transcriptase $\left(\right.$ RNase $\left.\mathrm{H}^{-}\right)$. Second strand cDNA synthesis was subsequently performed using DNA Polymerase I and RNase $\mathrm{H}$. Remaining overhangs were converted into blunt ends via exonuclease/polymerase activities. After adenylation of 3' ends of DNA fragments, NEBNext Adaptor with hairpin loop structure were ligated to prepare for hybridization. In order to select cDNA fragments of preferentially $150 \sim 200 \mathrm{bp}$ in length, the library fragments were purified with AMPure XP system (Beckman Coulter, Beverly, USA). Then $3 \mu$ l USER Enzyme (NEB, USA) was used with size-selected, adaptor-ligated cDNA at $37^{\circ} \mathrm{C}$ for $15 \mathrm{~min}$ followed by $5 \mathrm{~min}$ at $95^{\circ} \mathrm{C}$ before PCR. Then PCR was performed with Phusion HighFidelity DNA polymerase, Universal PCR primers and Index (X) Primer. At last, PCR products were purified (AMPure XP system) and library quality was assessed on the Agilent Bioanalyzer 2100 system.

The clustering of the index-coded samples was performed on a cBot Cluster Generation System using TruSeq PE Cluster Kit v3-cBot-HS (Illumina) according to the manufacturer's instructions. After cluster generation, the library preparations were sequenced on an Illumina Hiseq 2500 platform and 125 bp paired-end reads were generated.

The raw reads were cleaned by removing reads containing adapter, reads containing poly- $\mathrm{N}$ and low quality reads. High quality RNA-seq reads were pooled from Illumina sequencing of all samples and were then assembled into transcripts using Trinity (version 2.3.2) [56] with min-kmer-cov set to 2 by default and other parameters set at their defaults. After assembly, the longest transcripts of each gene were selected as the unigenes for subsequent analysis.

We quantified transcript levels in expected number of Fragments Per Kilobase of transcript sequence per Millions base pairs sequenced (FPKM) [57]. RSEM v1.3.0 was used to obtain FPKM values. RSEM used bowtie2 parameter mismatch 0 , (bowtie2 default parameters).

\section{Annotation and differential gene expression analysis}

The unigenes were annotated according to seven databases, NCBI blast (2.2.28+) was applied to search against the $\mathrm{Nr}$ database $\left(\mathrm{E}\right.$-value $\left.=1 \times 10^{-5}\right)$, Nt database (Evalue $\left.=1 \times 10^{-5}\right)$, Swiss-Prot database $\left(\right.$ E-value $\left.=1 \times 10^{-5}\right)$ and COG/KOG database $\left(\mathrm{E}-\mathrm{value}=1 \times 10^{-3}\right)$. Pfam annotation for the unigenes was finished using the HMMER 3.0 package [58], hmmscan (e-value $=0.01$ ). The unigenes were annotated using GO database by Blast2GO v2.5 [59] with the self-write script (e-value $=1 \times 10^{-6}$ ) on the basis of annotation results of $\mathrm{Nr}$ and Pfam. For KEGG annotation [60], the KAAS and KEGG Automatic Annotation Server [61] $\left(E\right.$-value $\left.=1 \times 10^{-10}\right)$ was conducted to confirm the metabolic pathways of unigenes.

Differential expression analysis of two stages was performed using the DESeq R package (1.10.1) [62]. DESeq provided statistical routines for determining differential expression in digital gene expression data using a model based on the negative binomial distribution. The resulting $p$ values were adjusted using the q value method proposed by Storey et al. [63]. Genes with an adjusted $p$ value $<0.05$ and an absolute value of $\log _{2}$ fold-change $>1$ found by DESeq were assigned as differentially expressed.

KEGG pathway enrichment analysis of the DEGs was done using KOBAS [61] with the hyper-geometric distribution model. For KEGG enrichment analysis, the pathway with a FDR value $\leq 0.05$ was considered as an enriched pathway.

\section{Quantitative real-time PCR validation of RNA-seq}

Nine genes with different expression patterns revealed by RNA sequencing were randomly selected for validation by qPCR. First strand cDNA was synthesized with TransSprit ${ }^{\circ}$ One-Step gDNA Removal and cDNA Synthesis SuperMix (TransGen Biotech, China) according to manufacturer's instructions. All cDNA were stored at $-20^{\circ} \mathrm{C}$ until use. Specific primers for each gene were designed according to the gene CDS sequences using Primer 3.0 software (http://bioinfo.ut.ee/primer3-0.4.0/) and are listed in Table S5. The 40S ribosomal protein S9-2-like (40S) gene was used as internal control (Additional file 11: Table S5). The qPCR was performed on a 7500 Fast Real Time PCR system (Life Technologies, USA) using $2 X$ SYBR qPCR Mix with low ROX concentration (Aidlab, China) according to the manufacturer's instruction. Four technical replicates were adopted for each sample. For each gene, the full sample set was run on the same plate to exclude any technical variation. Relative transcription levels were analyzed using the $2^{-\Delta \Delta C t}$ method. A regression analysis was performed between $\mathrm{qPCR}$ and RNA sequencing including all genes of the two reproductive modes at the six stages. 


\section{Conclusions}

In this study, it was concluded that different transcriptome regulating networks were developed between the sexual reproduction and apogamy in the fern. The genes regulating the apogamy initiation were more active than that in sexual reproduction. Then, the starch and sucrose metabolism relating to cell wall might play a key role in affecting apogamy initiation. The involved genes, such as TPS/TPP, SUS and SPS were regulated actively in this course. In addition, the hormone signal transduction pathway should play a prominent role in apogamy rather than sexual reproduction initiation. The candidate genes, including TIR1, ARF1, GID1, PP2C, $A B F$ and $M Y C 2$ were identified to participate in apogamy initiation. These results laid the foundation for revealing the molecular mechanisms of apogamy and would also be benefit for understanding the mechanisms related to asexual reproduction in higher plants. On the basis of the complicated apogamy and sexual reproduction transcriptomic changes in this study, further functional verification of the candidate genes and pathways would be needed in the future.

\section{Additional files}

Additional file 1: Figure S1. Length distribution of transcripts and unigenes in the assembled transcriptomes. The $x$ axis shows the lengths of transcripts/unigenes and the y axis shows the number of transcripts/ unigenes. (TIF $292 \mathrm{~kb}$ )

Additional file 2: Figure S2. Analysis of the BLAST results in $\mathrm{Nr}$ database. (a) Similarity distribution; (b) E-value distribution; (c) Best hit species classification. (TIF $101 \mathrm{~kb}$ )

Additional file 3: Figure S3. qRT-PCR validation of differential gene expression for two reproductive modes of gametophytes in Adiantum reniforme var. sinense. (PDF $85 \mathrm{~kb}$ )

Additional file 4: Table S1. The significantly enriched pathways of all the DEGs between SG0 and SG1. (XLSX $16 \mathrm{~kb}$ )

Additional file 5: Figure S4. The top-20 enriched KEGG pathways. a, SG0 vs SG1; b, AG0 vs AG1. The Y-axis represents the pathway term; the $X$-axis represents the rich factor. The sizes of the points represent different DEG numbers, such that the bigger the point, the greater the DEG number. The colors represent different q-values. (TIF $730 \mathrm{~kb}$ )

Additional file 6: Table S2. The significantly enriched pathways of all the DEGs between AG0 and AG1. (XLSX 45 kb)

Additional file 7: Table S3. Expression levels of genes involved in starch and sucrose metabolism pathway in gametophytes. (XLS 34 kb)

Additional file 8: Data S1. Sequences of genes involved in starch and sucrose metabolism pathway in gametophytes. (TXT $113 \mathrm{~kb}$ )

Additional file 9: Table S4. Genes associated with plant hormone signal transduction pathway. (XLS $27 \mathrm{~kb}$ )

Additional file 10: Data S2. Sequences of genes associated with plant hormone signal transduction pathway. (TXT $74 \mathrm{~kb}$ )

Additional file 11: Table S5. Gene IDs, descriptions and primer sequences for the nine genes used for qRT-PCR verification. (XLS 28 kb)

\section{Abbreviations}

ABA: Abscisic acid; ABF: ABRE binding factors; DEGs: Differential expressed genes; GID1: GIBBERELLIN INSENSITIVE DWARF1; GO: Gene Ontology; KEGG: Kyoto Encyclopedia of Genes and Genomes; KOG: euKaryotic Ortholog
Groups; Nr: NCBI non-redundant protein sequences; Nt: NCBI nucleotide sequences; PFAM: Protein family; PP2C: protein phosphatase 2C; qPCR: Quantitative real-time PCR; SPS: Sucrose-phosphate synthase; SUS: Sucrose synthase; TIR1: Transport inhibitor response protein 1; TPP: Trehalose 6-phosphate phosphatase; TPS: Trehalose 6-phosphate synthase

\section{Acknowledgments}

We kindly thank members from Beijing Novogene Bioinformatics Technology Co., Ltd. for their assistance with original data processing and related bioinformatic analysis.

Authors' contributions

QF and LQC designed the research; QF performed the experiments; QF analyzed the data; QF and LQC wrote the manuscript.

\section{Funding}

This work was supported by grants from National Natural Science Foundation of China (Grant No.31171996). The funding body had no contribution in the design of the study and collection, analysis, and interpretation of data and in writing the manuscript.

\section{Availability of data and materials}

Raw data supporting our findings can be found in the National Center for Biotechnology Information (NCBI) database under the accession number PRJNA548821.

Ethics approval and consent to participate

Not Applicable.

\section{Consent for publication}

Not Applicable.

\section{Competing interests}

The authors declare they have no competing interests.

\section{Author details}

${ }^{1}$ Key Laboratory of Horticultural Plant Biology, Ministry of Education/College of Horticulture and Forestry Sciences, Huazhong Agricultural University, Kunming 6502240, China. ${ }^{2}$ Southwest Research Center of Landscape Architecture Engineering (State Forestry and Grassland Administration), Southwest Forestry Universityy, Kunming 650224, China.

Received: 20 January 2019 Accepted: 30 June 2019

Published online: 09 July 2019

References

1. Fernandez $\mathrm{H}$, Revilla MA. In vitro culture of ornamental ferns. Plant Cell Tiss Org. 2003;73(1):1-13.

2. Cordle $A R$, Irish $\mathrm{EE}$, Cheng $\mathrm{CL}$. Apogamy induction in Ceratopteris richardii. Int J Plant Sci. 2007;168(4):361-9.

3. Gabancho LR, Prada C, Galan JMGY. Sexuality and apogamy in the Cuban Asplenium auritum-monodon complex (Aspleniaceae). Plant Syst Evol. 2010; 289(3-4):137-46.

4. Liu H-M, Dyer RJ, Guo Z-Y, Meng Z, Li J-H, Schneider H. The evolutionary dynamics of Apomixis in ferns: a case study from Polystichoid ferns. J Bot. 2012:2012:1-11.

5. Sheffield E, Bell PR. Current studies of the Pteridophyte life cycle. Bot Rev. 1987:53(4):442-90.

6. Menéndez $V$, Arbesú $R$, Somer $M$, Revilla A, Fernández $H$. From spore to sporophyte: how to proceed in vitro. In: Fernández H, Kumar A, Revilla MA, editors. Working with ferns: issues and applications. New York Dordrecht Heidelberg London: Springer Science+Business Media; 2011. p. 97-110.

7. Whittier DP, Steeves TA. Further studies on induced APOGAMY in ferns. Can J Bot. 2011;40(11):1525-31.

8. Whittier DP. Influence of osmotic conditions on induced apogamy in Pteridium gametophytes. Phytomorphology. 1975;25(2):246-49.

9. Elmore HW. The role of ethylene in the induction of apogamous buds in Pteridium gametophytes. Planta. 1973;111(1):85-90. 
10. Kwa SH, Wee YC, Lim TM, Kumar PP. IAA-induced apogamy in Platycerium coronarium (Koenig) Desv. Gametophytes cultured in vitro. Plant Cell Rep. 1995;14(9):598-602.

11. Martin KP, Sini S, Zhang CL, Slater A, Madhusoodanan PV. Efficient induction of apospory and apogamy in vitro in silver fern (Pityrogramma calomelanos L.). Plant Cell Rep. 2006;25(12):1300-7.

12. Okano Y, Aono N, Hiwatashi Y, Murata T, Nishiyama T, Ishikawa T, et al. A polycomb repressive complex 2 gene regulates apogamy and gives evolutionary insights into early land plant evolution. P Natl Acad Sci USA. 2009;106(38):16321-6.

13. Cordle AR, Irish EE, Cheng CL. Gene expression associated with apogamy commitment in Ceratopteris richardii. Sex Plant Reprod. 2012;25(4):293-304.

14. Bui LT, Pandzic D, Youngstrom CE, Wallace S, Irish EE, Szovenyi P, et al. A fern AINTEGUMENTA gene mirrors BABY BOOM in promoting apogamy in Ceratopteris richardii. Plant J. 2017:90(1):122-32.

15. Grossmann J, Fernandez H, Chaubey PM, Valdes AE, Gagliardini V, Canal MJ, et al. Proteogenomic analysis greatly expands the identification of proteins related to reproduction in the Apogamous Fern Dryopteris affinis ssp affinis. Front Plant Sci. 2017:8:336

16. Yang $X Y$, Zhang $X L$. Regulation of somatic embryogenesis in higher plants. Crit Rev Plant Sci. 2010:29(1):36-57.

17. Karami O, Saidi A. The molecular basis for stress-induced acquisition of somatic embryogenesis. Mol Biol Rep. 2010;37(5):2493-507.

18. Karami O, Aghavaisi B, Mahmoudi AP. Molecular aspects of somatic-toembryogenic transition in plants. J Chem Biol. 2009;2(4):177-90.

19. Liu XQ, Chen LQ. Genetic variation in the endangered fern Adiantum reniforme var. sinense (Adiantaceae) in China. Ann Bot Fenn. 2007:44(1):25-32.

20. Wu H, Liu XQ, Ji H, Chen LQ. Effects of light, macronutrients, and sucrose on germination and development of the endangered fern Adiantum reniforme var. sinense (Adiantaceae). Sci Hortic. 2010;125(3):417-21.

21. Der JP, Barker MS, Wickett NJ, de Pamphilis CW, Wolf PG. De novo characterization of the gametophyte transcriptome in bracken fern, Pteridium aquilinum. BMC Genomics. 2011;12:99.

22. Aya K, Kobayashi M, Tanaka J, Ohyanagi H, Suzuki T, Yano K, et al. De novo transcriptome assembly of a fern, Lygodium japonicum, and a web resource database, Ljtrans DB. Plant Cell Physiol. 2015;56(1):e5.

23. Brill E, Thournout MV, White RG, Llewellyn D, Campbell PM, Engelen S, et al. A novel isoform of sucrose synthase is targeted to the Cell Wall during secondary Cell Wall synthesis in cotton fiber. Plant Physiol. 2011;157(1):40.

24. Coleman HD, Yan J, Mansfield SD. Sucrose synthase affects carbon partitioning to increase cellulose production and altered cell wall ultrastructure. Proc Natl Acad Sci U S A. 2009;106(31):13118-23.

25. Huber SC, Huber JL. Role and regulation of sucrose-phosphate synthase in higher plants. Annu Rev Plant Physiol Plant Mol Biol. 1996;47(2):431.

26. Joko T, Subandi A, Kusumandari N, Wibowo A, Priyatmojo A. Activities of plant cell wall-degrading enzymes by bacterial soft rot of orchid. Arch Phytopathol Plant Protect. 2014;47(10):1239-50.

27. Ali MB, Abugoukh AA. Changes in Pectic substances and Cell Wall degrading enzymes during tomato fruit ripening. Univ Khartoum J Agric Sci. 2005;13(2):202-23.

28. Paramita $V$, Yulianto ME. Effect of $\beta$-glucosidase activity on the vanillin enzymatic formation by using rumen liquid for cell walls degradation. J Food Res. 2013;2(2):65-9.

29. Iraqi D, Tremblay FM. The role of sucrose during maturation of black spruce ( Picea mariana) and white spruce ( Picea glauca) somatic embryos. Physiol Plant. 2001;111(3):381-8.

30. Konradova H, Lipavska H, Albrechtova J, Vreugdenhil D. Sucrose metabolism during somatic and zygotic embryogeneses in Norway spruce: content of soluble saccharides and localisation of key enzyme activities. J Plant Physiol. 2002;159(4):387-96.

31. Lipavská H, Konrádová H. Somatic embryogenesis in conifers: the role of carbohydrate metabolism. In Vitro Cell Dev Biol Plant. 2004;40(1):23-30.

32. Satoh-Nagasawa N, Nagasawa N, Malcomber S, Sakai H, Jackson D. A trehalose metabolic enzyme controls inflorescence architecture in maize. Nature. 2006;441(7090):227-30

33. Chary SN, Hicks GR, Choi YG, Carter D, Raikhel NV. Trehalose-6-phosphate synthase/phosphatase regulates cell shape and plant architecture in Arabidopsis. Plant Physiol. 2008;146(1):97-107.

34. van Dijken AJH, Schluepmann H, Smeekens SCM. Arabidopsis trehalose-6phosphate synthase 1 is essential for normal vegetative growth and transition to flowering. Plant Physiol. 2004;135(2):969-77.
35. Pellny TK, Ghannoum O, Conroy JP, Schluepmann H, Smeekens S, Andralojc J, et al. Genetic modification of photosynthesis with E. coli genes for trehalose synthesis. Plant Biotechnol J. 2004;2(1):71-82.

36. Wei Z, Qu Z, Zhang L, Zhao S, Bi Z, Ji X, et al. Overexpression of poplar xylem sucrose synthase in tobacco leads to a thickened cell wall and increased height. PLoS One. 2015;10(3):e0120669.

37. Gomez LD, Baud S, Gilday A, Li Y, Graham IA. Delayed embryo development in the ARABIDOPSIS TREHALOSE-6-PHOSPHATE SYNTHASE 1 mutant is associated with altered cell wall structure, decreased cell division and starch accumulation. Plant J. 2006;46(1):69-84.

38. Gomez LD, Baud S, Graham IA. The role of trehalose-6-phosphate synthase in Arabidopsis embryo development. Biochem Soc T. 2005;33: 280-2.

39. Menendez V, Villacorta NF, Revilla MA, Gotor V, Bernard P, Fernandez H. Exogenous and endogenous growth regulators on apogamy in Dryopteris affinis (Lowe) Fraser-Jenkins sp affinis. Plant Cell Rep. 2006;25(2):85-91.

40. Wang $\mathrm{YH}$, Irving HR. Developing a model of plant hormone interactions. Plant Signal Behav. 2011;6(4):494-500.

41. Kulaeva ON, Prokoptseva OS. Recent advances in the study of mechanisms of action of phytohormones. Biochemistry. 2004;69(3):233-47.

42. Wójcikowska B, Gaj MD. Expression profiling of AUXIN RESPONSE FACTOR genes during somatic embryogenesis induction in Arabidopsis. Plant Cell Rep. 2017;36(6):1-16.

43. Raghavan V. Molecular embryology of flowering plants: Section IV adventive embryogenesis. Cambridge: Cambridge University Press; 1997.

44. Leyser O. Molecular genetics of auxin signaling. Annu Rev Plant Biol. 2002; 53(53):377-98.

45. Gee MA, Hagen G, Guilfoyle TJ. Tissue-specific and organ-specific expression of soybean auxin-responsive transcripts GH3 and SAURs. Plant Cell. 1991; 3(4):419-30.

46. Gomez MD, Ventimilla D, Sacristan R, Perez-Amador MA. Gibberellins regulate ovule integument development by interfering with the transcription factor ATS. Plant Physiol. 2016;172(4):2403-15.

47. Gupta R, Chakrabarty SK. Gibberellic acid in plant: still a mystery unresolved. Plant Signal Behav. 2013;8(9):ii.

48. Griffiths J, Murase K, Rieu I, Zentella R, Zhang ZL, Powers SJ, et al. Genetic characterization and functional analysis of the GID1 gibberellin receptors in Arabidopsis. Plant Cell. 2006;18(12):3399-414.

49. Gallego-Giraldo C, Hu J, Urbez C, Gomez MD, Sun TP, Perez-Amador MA Role of the gibberellin receptors GID1 during fruit-set in Arabidopsis. Plant J Cell Mol Biol. 2014;79(6):1020-32.

50. Ferreira LG, Dusi DMD, Irsigler AST, Gomes ACMM, Mendes MA, Colombo L, et al. GID1 expression is associated with ovule development of sexual and apomictic plants. Plant Cell Rep. 2018;37(2):293-306.

51. Née G, Kramer K, Nakabayashi K, Yuan B, Yong X, Miatton E, et al. DELAY OF GERMINATION1 requires PP2C phosphatases of the ABA signalling pathway to control seed dormancy. Nat Commun. 2017;8(1):72.

52. Chen J, Zhang D, Zhang C, Xia X, Yin W, Tian Q. A putative PP2C-encoding gene negatively regulates $A B A$ signaling in Populus euphratica. PLoS One. 2015;10(10):e0139466.

53. Sakata Y, Komatsu K, Taji T, Tanaka S. Role of PP2C-mediated ABA signaling in the moss Physcomitrella patens. Plant Signal Behav. 2009;4(9):887-9.

54. Liu JH, Huang XS, Chen XJ. Overexpression of PtrABF gene, a bZIP transcription factor isolated from Poncirus trifoliata, enhances dehydration and drought tolerance in tobacco via scavenging ROS and modulating expression of stress-responsive genes. BMC Plant Biol. 2010;10(1):230.

55. Hong GJ, Xue XY, Mao YB, Wang LJ, Chen XY. Arabidopsis MYC2 interacts with DELLA proteins in regulating Sesquiterpene synthase gene expression. Plant Cell. 2012;24(6):2635-48.

56. Grabherr MG, Haas BJ, Yassour M, Levin JZ, Thompson DA, Amit I, et al. Fulllength transcriptome assembly from RNA-Seq data without a reference genome. Nat Biotechnol. 2011;29(7):644-52

57. Trapnell C, Williams BA, Pertea G, Mortazavi A, Kwan G, van Baren MJ, et al. Transcript assembly and quantification by RNA-Seq reveals unannotated transcripts and isoform switching during cell differentiation. Nat Biotechnol. 2010;28(5):511-5.

58. Zhang Z, Wood WI. A profile hidden Markov model for signal peptides generated by HMMER. Bioinformatics. 2003;19(2):307-8.

59. Gotz S, Garcia-Gomez JM, Terol J, Williams TD, Nagaraj SH, Nueda MJ, et al. High-throughput functional annotation and data mining with the Blast2GO suite. Nucleic Acids Res. 2008;36(10):3420-35. 
60. Kanehisa M, Araki M, Goto S, Hattori M, Hirakawa M, Itoh M, et al. KEGG for linking genomes to life and the environment. Nucleic Acids Res. 2008; 36(Database issue):D480-4.

61. Mao XZ, Cai T, Olyarchuk JG, Wei LP. Automated genome annotation and pathway identification using the KEGG Orthology (KO) as a controlled vocabulary. Bioinformatics. 2005;21(19):3787-93.

62. Anders S, Huber W. Differential expression analysis for sequence count data. Genome Biol. 2010;11(10):R106.

63. Storey JD, Tibshirani R. Statistical significance for genomewide studies. P Natl Acad Sci USA. 2003;100(16):9440-5.

\section{Publisher's Note}

Springer Nature remains neutral with regard to jurisdictional claims in published maps and institutional affiliations.

Ready to submit your research? Choose BMC and benefit from:

- fast, convenient online submission

- thorough peer review by experienced researchers in your field

- rapid publication on acceptance

- support for research data, including large and complex data types

- gold Open Access which fosters wider collaboration and increased citations

- maximum visibility for your research: over $100 \mathrm{M}$ website views per year

At BMC, research is always in progress.

Learn more biomedcentral.com/submissions 